
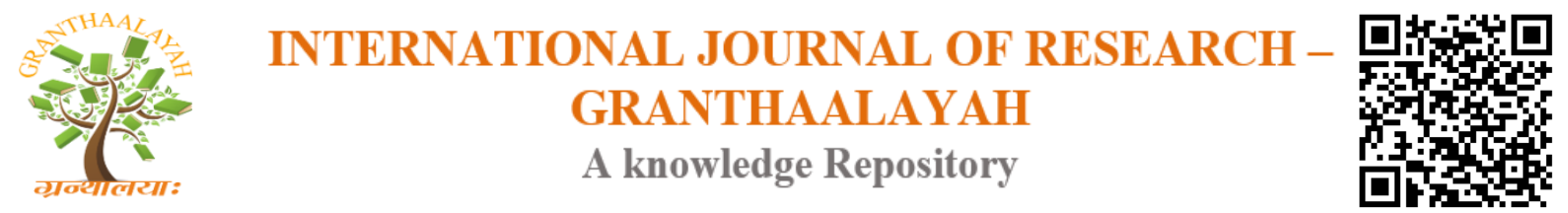

Management

\title{
LOCAL COMMUNTIES ATTITUDES AND PERCEPTIONS TOWARDS COMMUNITY BASED TOURISM IN IKO-ESAI COMMUNITY, CROSS RIVER STATE, SOUTH EAST, NIGERIA
}

\author{
Nchor A. A. ${ }^{* 1}$, Agbor C. O. ${ }^{2}$ \\ ${ }^{* 1,2}$ Department of Forestry and Wildlife Resources Management, University of Calabar, Nigeria
}

\begin{abstract}
The role of local communities' attitudes and perceptions in the determination of tourism development in host destination are critical and cannot be overemphasized. The study sought to determine the perceptions of local residents towards tourism development in Iko-Esai Community of Cross River State, Nigeria. Questionnaires and interviews were used to collect primary data while secondary data was sourced from documents in CERCOPAN Office, journals, as well as past studies in the area. A total of one hundred and forty-six (146) questionnaires were administered to respondents in two (2) selected wards in the community. Data was analyzed using frequencies and percentages. Results showed overwhelming agreement by respondents that the community is fully involved in all the activities of tourism development in the area including benefit sharing, decision making, as well as the overall management of tourism. $54.11 \%$ of respondents agreed that ecotourism has contributed positively to poverty alleviation while $57.54 \%$ of the respondents sampled were of the opinion that profit form ecotourism is distributed directly or indirectly to indigenes. Ecotourism has successfully enhanced cooperation between the local communities and external bodies as reflected in the position of $97.94 \%$ of the respondents. The respondents were of the views that CERCOPAN - an NGO operating a primate rehabilitation project in the community has been working closely with them to save the primates in the area from further population depletion. On benefit sharing, $91.78 \%$ of the respondents sampled agreed that the community participated in sharing economic benefits from ecotourism while $67 \%$ of the respondents were of the opinion that length of residency in the community affects people's attitudes and perceptions towards tourism development. Though there was a report of human-wildlife conflicts in the area, a greater percentage of the respondents $(69.87 \%)$ were of the opinion that the conflicts were not a problem in the community as the challenge was averted because of the fencing of the area by CERCOPAN. CERCOPAN should encourage the community to step up their support for tourism development in the area through increased benefit sharing and the development of some basic infrastructures like health centers and water projects in the community.
\end{abstract}

Keywords: Local Communities; Tourism Development; Host Destination; Local Residents; Benefit Sharing. 
Cite This Article: Nchor A. A., and Agbor C. O.. (2018). "LOCAL COMMUNTIES ATTITUDES AND PERCEPTIONS TOWARDS COMMUNITY BASED TOURISM IN IKOESAI COMMUNITY, CROSS RIVER STATE, SOUTH EAST, NIGERIA." International Journal of Research - Granthaalayah, 6(1), 69-79. 10.29121/granthaalayah.v6.i1.2018.1595.

\section{Introduction}

It has become widely recognized that planners and entrepreneurs within the tourism sector should take the views of host communities into account if the industry is to be sustainable in the long term and promote meaningful tourism development (Allen et al., 1988). Furthermore, commercial tourism has always come under various challenges due to uncompromising position of host communities. Despite this, researches into the antecedents of people's reactions on tourism development have helped planners in understanding why people support or oppose tourism. Most of the tourism practiced within and around Iko-Esai is wildlife based, and involves game viewing including the conservation of the flora and fauna in the area.

The success of any tourism project that is planned and implemented without the involvement and support of the local communities is bound to fail. Local community reactions and the factors that influence their attitudes and perceptions are crucial in achieving local support for tourism development and wildlife conservation (Fridgen, 1991). Thus, the reactions of local communities in the area of tourism development and wildlife conservation have been extensively studied by many researchers (Murphy, 1985; Gunn, 1988; Gee, Mackens et al., 1989), giving rise to suggestions that most local communities around protected areas are influenced by perceived impacts of tourism manifested through economic, environmental and social costs and benefits. This study is targeted towards assessing local people's attitudes and perceptions towards community based tourism development in Iko-Esai community.

\section{Materials and Methods}

Iko-Esai is located in Akamkpa Local Government Area of Cross River State a distance of 90km North of Calabar, the capital of Cross River State, South East, Nigeria. The Community has a total landmass of about 21,000hectares.

The temperature of Iko-Esai community ranges from $23-37^{\circ} \mathrm{C}$ with a relative humidity of 90 $100 \%$ in the rainy season and $70-80 \%$ in the dry season. The area is characterized by high rainfall with an average of 3,000 mm per annum being recorded, while the dry season, last for up to four (4) months (December to March).

Iko-Esai community consists of a moist tropical lowland forest in its natural state. The area has about 12,000 hectares of community forest which is managed by the community and CERCOPAN including 400 hectares curbed out as core area for intensive protection, 4000hectares as research area co-managed by CERCOPAN and the community and 3000hectares as farmlands. The soil is deep and well drained with high humus content.

The area consists of a rich diversity of wildlife species ranging from the small Primates including gallagoes and Potos to medium size monkeys of the genus Cercopithecus and Cercocerbus 
species to large primates which includes chimpanzees and lowland gorillas. The area also consists of a wide variety of ungulates species like duikers as well as golden cats, elephants, buffalos, countless species of birds and numerous butterfly species.

\subsection{Method of Data Collection}

The study adopted the exploratory design to generate the required information. Exploratory designs allow the researcher to make a comprehensive influence about the investigated variable in the target population (Burns, 2000).

\subsection{Target Population}

A total of $5.57 \%$ of the total population of Iko-Esai Community (2693) was sampled. The 5.57\% represented one hundred and fifty (150) individuals as the population of study drawn from two (2) wards (Eyeyeng and Okoyong) randomly selected in the community.

\subsection{Source of Data}

The sources of data for this study were collected from primary and secondary sources. The primary sources of data used in the course of carrying out this research work are from reconnaissance survey, personnel observations in the community, oral interview and the use of questionnaires structured around a Likert Scale (Ko and Steward, 2002). A total of seventy five (75) were administered in each ward covering one hundred and fifty (150) questionnaires however only one hundred and forty-six questionnaires were completed and returned. Secondary sources of data used for the literature review are information gathered from existing works relating to the study from libraries, journals, textbooks and the internet.

\subsection{Statistical Analysis}

Data collected was analyzed and results presented using tables and graphs while descriptive statistics was used to determine frequencies and percentages.

\section{Results and Discussions}

\subsection{Results}

\section{Local Community Involvement and Participation}

Figure 1 below is the reflection of the respondents on the opinion on the level of involvement by local communities in community based tourism 


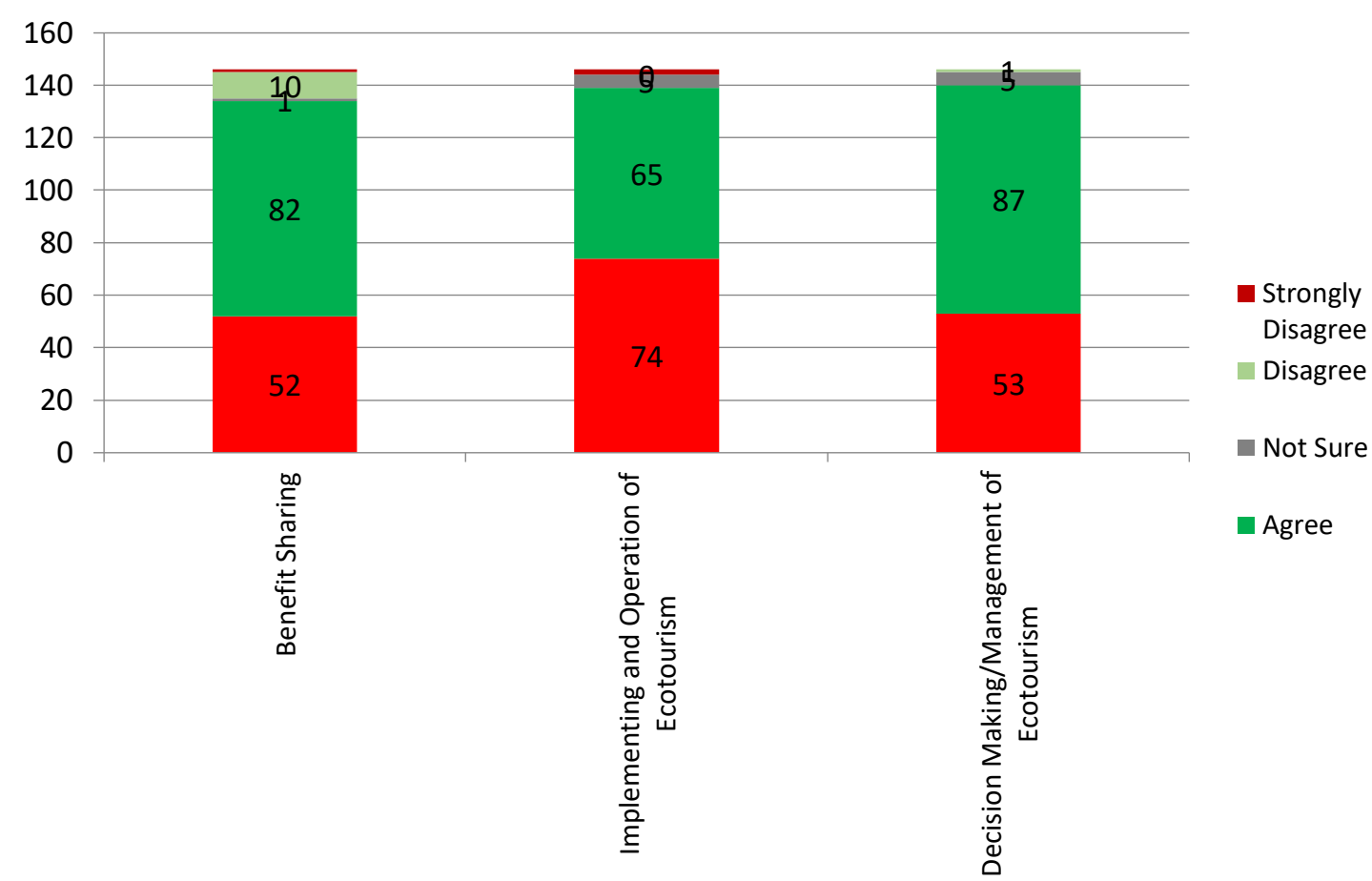

Figure 1: Involvement of Iko-Esai Community in Ecotourism Development

The result shows an overwhelming agreement by respondents that the community is fully involved in all the activities of tourism development in Iko-Esai including benefit sharing, decision making/management of ecotourism as well as implementing and operation of ecotourism.

\section{Poverty Alleviation}

\section{Poverty Alleviation in Ecotourism}

The results from respondents on the role of ecotourism in poverty alleviation is shown in table 1 below.

Table 1: Poverty alleviation and ecotourism

\begin{tabular}{|l|l|l|l|l|}
\hline Response & Eyeyeng & Okoyong & Total & Percentage of Total (\%) \\
\hline Strongly agree & 10 & 13 & 23 & 15.75 \\
\hline Agree & 25 & 31 & 56 & 38.36 \\
\hline Not Sure & 24 & 7 & 31 & 21.23 \\
\hline Disagree & 13 & 20 & 33 & 22.60 \\
\hline Strongly Disagree & 3 & 0 & 3 & 2.06 \\
\hline Total & 75 & 71 & 146 & $100 \%$ \\
\hline
\end{tabular}

Source: Field Survey, 2010

Before the engagement of CERCOPAN in conservation and tourism activities in the community, the local level of poverty in the community was very high. However, the activities of CERCOPAN in the areas of wildlife conservation and tourism development has provided job opportunities for the people and also created opportunities for the local people to exploit the presence of visitors to increase their socio-economic status. 


\section{Income and Profit Distribution to Indigenes from Ecotourism}

Table 2 below is the result of response from respondents on the distribution of profit and income to indigenes from proceeds accruing from ecotourism activities in the study area.

Table 2: Income and profit distribution to indigenes from ecotourism

\begin{tabular}{|l|l|l|l|l|}
\hline Response & Eyeyeng & Okoyong & Total & Percentage of Total (\%) \\
\hline Strongly agree & 13 & 21 & 34 & 23.29 \\
\hline Agree & 28 & 22 & 50 & 34.25 \\
\hline Not Sure & 12 & 7 & 19 & 13.01 \\
\hline Disagree & 22 & 15 & 37 & 25.34 \\
\hline Strongly Disagree & 0 & 6 & 6 & 4.11 \\
\hline Total & 75 & 71 & 146 & $100 \%$ \\
\hline
\end{tabular}

Source: Field Survey, 2010

The direct and indirect distribution of profits from ecotourism to indigenes will increase the livelihood capacity of the local communities. This will enhance their socio-economic wellbeing if sustained.

\section{Local Community Partnerships}

\section{Enhancement of Cooperation from External Bodies}

Figure 2 below is the result of respondent's position on if there is an effective enhancement of cooperation between local communities and external bodies.

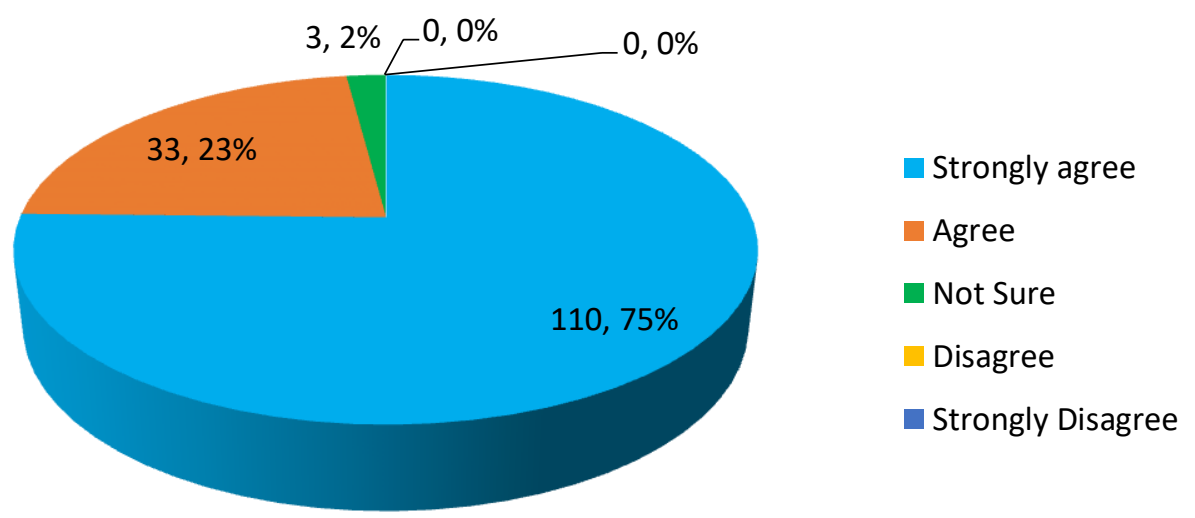

Figure 2: Enhancement of Cooperation from External Bodies

Source: Field Survey, 2010

The strong and effective collaboration between the local communities and other agencies including CERCOPAN, Cross River State Forestry Commission, Cross River National Park and CERCOPAN Development Committee will definitely enhance successful implementation of tourism development projects in the area.

\section{Benefit Sharing}

Figure 3 is a reflection on the position of respondents on the sharing of benefits between the community and the partners. 


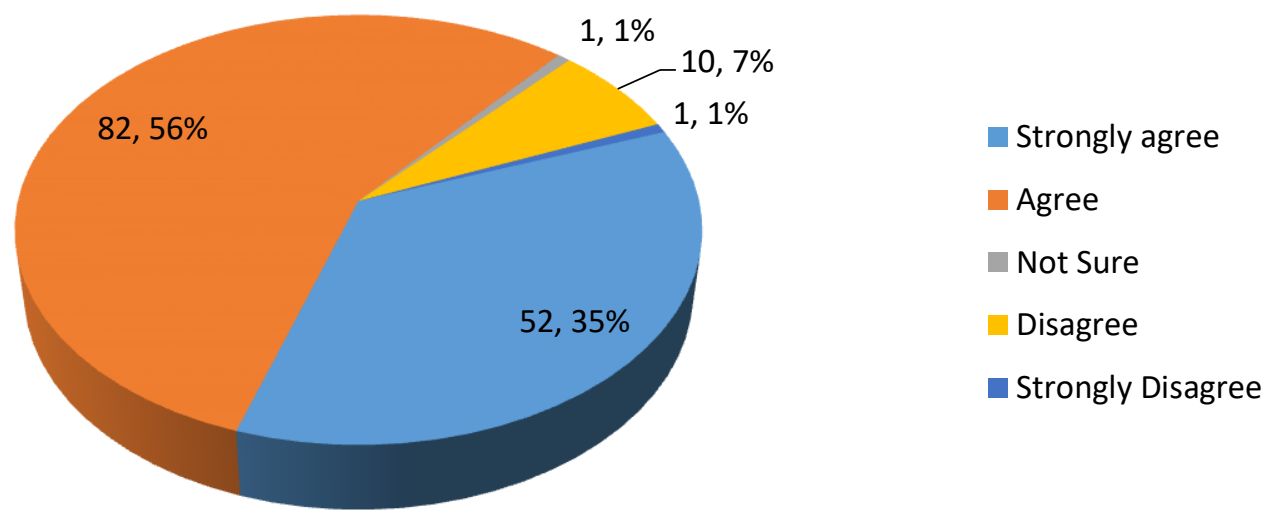

Figure 3: Ecotourism and community participation in benefit sharing Source: Field Survey, 2010

The overwhelming response from respondents supporting the use of benefit sharing in the management of Community Based Tourism and Conservation generally is an indication that the local communities in the study area will be supportive of all the activities that are targeted towards conservation programmes in the area.

\section{Length of Residency}

Figure 4 below is a result of respondent's opinion on the impact of length of residency on the attitude and perceptions of local people towards tourism development.

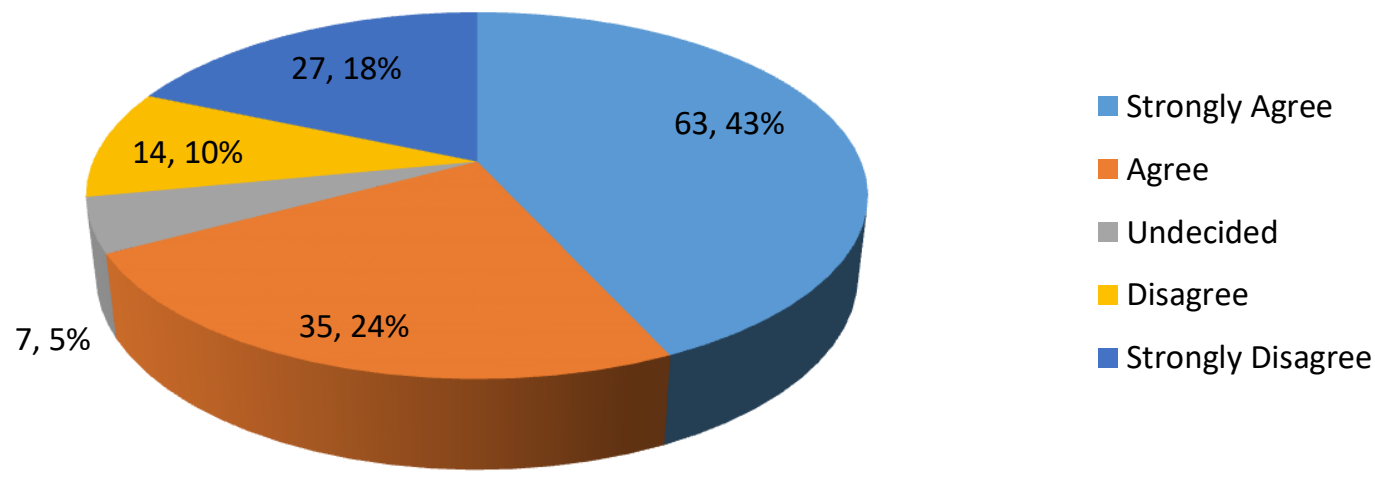

Source: Field Survey, 2010

Figure 4: Length of Residency

The result above shows that the longer a person stays in a particular environment, the more the person has passion for the environment.

\section{Human Wildlife Conflict}

The results on respondent's position regarding problems of human wildlife conflict are shown in table 3 below. 
Table 3: Problem of conflicts due to interest of indigenes

\begin{tabular}{|l|l|l|l|l|}
\hline Response & Eyeyeng & Okoyong & Total & Percentage of Total (\%) \\
\hline Agree & 37 & 23 & 60 & 41.10 \\
\hline Strongly Agree & 22 & 20 & 42 & 28.77 \\
\hline Not Sure & 9 & 7 & 16 & 10.96 \\
\hline Strongly Disagree & 1 & 6 & 7 & 4.79 \\
\hline Disgree & 6 & 15 & 21 & 14.38 \\
\hline Total & 75 & 71 & 146 & $100 \%$ \\
\hline
\end{tabular}

Source: Field Survey, 2010

From the overall results above, it was reported that human wildlife conflicts exist however this was not a challenge in the community due to the intervention of CERCOPAN through the provision of fences to check movement of wildlife species randomly.

\subsection{Discussions}

\section{Local Community Involvement and Participation}

Generally, most of the respondents agreed with the statement that local people were involved in tourism development in Iko-Esai. However, a lower proportion disagreed with the same statement. This may be partly due to the fact that some members of the community were regularly consulted by CERCOPAN when issues regarding human-wildlife conflict are reported to the organization. CERCOPAN also undertakes outreach activities like awareness creation through education and extension programmes among local people.

Local people require direct participation in decision making on planning and management activities as well as tourism development programmes. This form of involvement was demonstrated by the study results as shown in figure 1 . Most of the people interviewed stated that they were not only involved in the decision making process but in meetings that provided them with the opportunity of deciding on projects that will be of immense benefits to the people. This position is in line with those of Tosun, (2006) and Byers (1996) who alluded that in pastoral areas sustainable natural resource management requires integrating the values and interests of a range of stakeholders who have the most direct interest in the local natural resource base.

\section{Poverty Alleviation}

The position by majority of the respondents that local people participated in wildlife conservation may be explained by the fact that they had been given so much enlightenment on the need to conserve the wildlife resources in the area. Participation is a process designed to develop and strengthen the capacities of local people to gain responsibility for and authority over natural resources, and effectively contribute to all decisions on how these resources are sustainably utilized (Barrow, 1996). It is a fact that taking part actively in wildlife conservation and tourism decision-making processes is an integral aspect of involving local community members in tourism development and this helps in developing positive attitudes and perceptions towards the growth of the industry.

There is need to include local communities in wildlife management though there is debate about the degree of inclusion in the decision-making process to be exercised by local people. Most of 
the proposals range from passive participation where people participate by being told what has been decided or has already taken place to active participation where people get involved at the commencement stage of the project (Tosun, 2006). This is expected to engage local people to all aspects of tourism development in the area and make them feel proud and happy and hence develop positive attitudes and perceptions towards wildlife and tourism development. The most desired way of involving the local community in wildlife conservation and tourism development appears to represent "spontaneous participation" (Tosun, 2006). This typology advocates for a bottom-up and active participation by local people. Drake (1991) defines local participation as the ability of the local community to influence the outcomes of development projects, for example ecotourism, that have socio-economic impact on their lives. Involving local communities in tourism development in Iko-Esai is a good development that would not only minimize the cost of managing and conserving the resources in the area but also helps in changing the attitudes and perceptions of the local people towards wildlife conservation and tourism development in the area.

Poverty could be the main reason why local communities around protected areas engage in illegal activities like poaching, collection of NTFPs and firewood. Local people's attitudes and perceptions are influenced by the benefits they derive. This contradicts with the position of Kilele and Ndeng'e (2003) that pre-supposes that the people's contribution towards tourism development becomes low when poverty level is very high irrespective of the benefits they enjoy. It can be assumed that the involvement of Iko-Esai community in benefit sharing might be attributed to their support for conservation and tourism development regardless of the poverty situation in the community. Most of the local community members living $5 \mathrm{~km}$ from the park boundary were found to be poor and cannot afford energy from electricity or kerosene. Consequently, they destroy trees in the park to get firewood and do not plant trees on their land since the parcels of land they own are too small. Some sections of the Park are covered by grass and are frequently burned by accidental fires. During the dry season, when farmers are preparing their lands using fire, it accidentally gets out of control and crosses into the park causing a lot of damage to wildlife and their habitat. Illiteracy level is also a factor which has hindered community participation in tourism development. Although results showed that most of the residents had gone to school they ignore that wildlife is directly and indirectly important to them since the whole country earns revenue from tourism development. Despite this, education, training and raising awareness remain the doorways to effective community participation and empowerment in wildlife conservation and tourism development (Gamassa, 2001). Lack of a community participation policy in park management has made local people to feel marginalized. This lack, coupled with hostility from the park management staff makes the local people to detest wildlife resulting in local people's low participation in wildlife conservation and management. Low participation may also be attributed to poor and ineffective communication between Park Authorities and the local people.

\section{Local Community Partnerships}

\section{Benefit Sharing}

The amount and type of benefits received influences the attitudes and perceptions towards tourism development. The significantly higher proportion of respondents who agreed with the position that community members are involved in benefit sharing might explain that the amount 
and type of benefit that local people derive from tourism development may be explained the fact that benefits normally motivate individuals and groups to take positive action towards conservation and tourism development. Many communities in protected areas do not receive benefits and yet they bear the costs of living with wildlife (Kiss, 1990). Consequently, they develop negative attitudes towards conservation (Omondi, 1994; Hill 1998).

\section{Effect of reaping benefits on the attitudes and perceptions of local people towards tourism development}

Generally, benefits boost positive attitudes and perceptions towards conservation and tourism development (Byer, 1996).

\section{Length of Residency}

From the results of the study, a significant high proportion of the respondents were of the view that length of residence had influence on the attitude and perceptions of local people towards tourism development in the community. The reason for this development stems from the fact that the longer one resides in an area, the more the person becomes aligned and passionate to issues related to wildlife in the area. This position is further strengthened by the fact that the environmental NGO operating in the community has built in a strong environmental conservation awareness programme to sensitize the people on the need to protect wildlife resources in the area. Similar concerns are also shared by Mc Cool and Martin (1994) that residents who are strongly attached to their communities view tourism development challenges with more passion than non-residents.

\section{Human Wildlife Conflict}

Hostility of the park management staff towards local people and its impacts on their attitudes and perceptions towards tourism development

One of the challenges associated with tourism development has been how to control the local people's use of land and wildlife resources in a manner that there will be no conflict, thus meeting both tourism development and local people's needs (Ngare, 1995). In the case of IkoEsai community, the 400 hectares of land provided by the community to CERCOPAN for primate rehabilitation is fenced. This intervention is thought to be highly effective in mitigating human wildlife conflict (Thouless and Sakwa, 1995).

Generally, it has been suggested that human wildlife conflict should be minimized for a successful implementation of community based tourism in local communities. This can be achieved by providing adequate compensation for loss of crop and property, supporting victims of animal injury or death, equitable share of the tourism revenue and assisting in compensating for loss or damage of crops. These measures if properly applied will promote positive attitudes and perception among local communities and will further enhance their support for wildlife conservation and tourism development.

\section{Conclusions and Recommendations}

The perceived involvement of Iko-Esai Community in the wildlife conservation and development of ecotourism in the community is a major boost in the success of Community 
Based Ecotourism in the area. This is supported by the distribution of income and profits emanating from revenue accruing from tourists.

It is therefore recommended that the ecotourism potentials in Iko Esai community not yet harnessed for visitors' use including Bagamokum Mountain, Ikibitoi Mountain, Agorum Ekpun and Owai Peak sites should be properly designed and developed to expand the tourism potentials of the area.

\section{Acknowledgements}

The authors wish to thank the field staff of CERCOPAN and CERCOPAN Development Committee in Iko-Esai for their contributions towards the administration of questionnaires to respondents and the use of reports in CERCOPAN office to support the gathering of data for the study.

\section{References}

[1] Allen L. R., Long P. T., Perdue R. R., \& Kieselbach S. (1988). The Impact of Tourism Development on Residents' Perception of Community Life. Journal of Travel Research, 27(1). 16 $-21$

[2] Fridgen, J.D. (1991). Dimension of Tourism. East Lansing MI: The Educational Institute of the American hotel and Motel association.

[3] Murphy, P. (1985) Tourism: A Community Approach. New York: Methuen.

[4] Gunn C. A. (1988). Tourism Planning. Taylor \& Francis, New York, NY.

[5] Gee C. Y., Mackens J. C. \& Choy, D. J. (1989). The Travel Industry. Van Nostrand Reinhold. New York, NY.

[6] Burns, (2000). Methods of Research, London: Irwin.

[7] Ko, D.W. and Steward, W.P. (2002). A Structural Equation Model of Resident Attitude for Tourism Development. Tourism management 23(5): 521-530.

[8] Tosun, C. (2006). Expected nature of community participation in tourism development. Tourism Management 27:493-504.

[9] Byers, A. (1996). Understanding and influencing behaviuor in conservation and natural resources management. Africa biodiversity series. Washington D.C. Biodiversity supply programme.

[10] Barrow, G.C. (1996). The drylands of Africa, local participation in the management initiative publisher, Nairobi Kenya.

[11] Drake, S.P. (1991). Local participation in Ecotourism Projects. In Whelan, T. ed. Nature Tourism: managing for the Environment. Island Press. Washington DC.

[12] Kilele, A.K.M. and Ndengeee, G.K. (2003). Poverty Mapping: The case of Kenya. Kenya Institute of Public Policy Research, Nairobi, Kenya.

[13] Gamassa, D.M. (1994). Community based conservation, paper presented at the Institute of Continuing Education, Sokoine University of Agriculture, Morogoro. Tanzania.

[14] Kiss, A. (1990). Living with Wildlife: Wildlife Resources Management with Local Participation in Africa.World Bank Technical Report. No. 103: 10-11.

[15] Omondi. P. (1994). Wildlife -Human conflict in Kenya: Integrating wildlife conservation with human needs in the Maasai Mara region. Unpublished DPhil thesis, Mc Gill University.

[16] Hill, C.M. (1998). Conflicting attitudes towards elephants around the Budongo forest reserve, Uganda. Environs Conservation, 25: 244-250.

[17] McCool, S., and S. Martin (1994) Community Attachment and Attitudes Toward Tourism Development. Journal of Travel Research 32(3):29-34. 
[18] Ngare, P. M. (1995). Integration of the local community into wildlife conservation: a case study of Lamuria and central division of Laikipia District, Kenya. M.phil Thesis, Moi University, Eldoret, Kenya.

[19] Thouless, C.R., and Sakwa, J. (1995). Shocking elephants: fences and crop raiders in Laikipia District, Kenya. Biological conservation vol. 72: 99-107.

\footnotetext{
*Corresponding author.

E-mail address: nchorayuk@ yahoo.com
} 